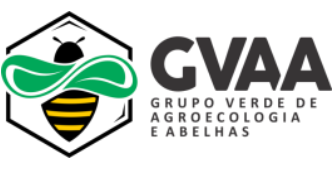

\title{
Conhecimento de plantas alimentícias não convencionais em assentamentos rurais
}

\section{Knowledge of unconventional food plants in rural settlements}

\author{
Simone Braga Terra ${ }^{(1}{ }^{1}$; Bruna Pereira Ferreira ${ }^{2}$
}

${ }^{1}$ Doutora, Engenheira Agrônoma, Professor Adjunto da Universidade Estadual do Rio Grande do Sul, Unidade de Santana do Livramento, Santana do Livramento, Rio Grande do Sul, +55 55 3244-1440. E-mail: simone-terra@uergs.edu.br. ${ }^{2}$ Bolsista de Iniciação Científica. Curso de Bacharelado em Agronomia. Universidade Estadual do Rio Grande do Sul. Santana do Livramento, Rio Grande do Sul. E-mail: bruna-ferreira01@uergs.edu.br.

N O T A
C IE N TÍFI C A

Recebido: 07/01/2020

Aprovado: 25/03/2020

Palavras-chave:

Agricultura familiar

Soberania alimentar

Bioma Pampa

PANC
Key words:

Family farming

Food sovereignty

Biome Pampa

PANC

\section{R E S U M O}

Plantas alimentícias não convencionais (PANC) refere-se a todas as plantas que possuem uma ou mais partes comestíveis para humanos, sendo espontâneas ou cultivadas, nativas ou exóticas, que não estão incluídas em nosso cardápio cotidiano. Agricultores familiares, ao terem consciência do potencial dessas plantas alimentícias, podem diversificar sua alimentação habitual e cultivá-las aproveitando áreas improdutivas ou de baixa fertilidade. Com isso, objetivou-se avaliar o nível de conhecimento de agricultores moradores em assentamentos rurais sobre as PANC, identificando as espécies presentes nos locais estudados. A pesquisa foi realizada entre março e junho de $2019 \mathrm{em}$ três assentamentos da reforma agrária de Santana do Livramento, Rio Grade do Sul, com 15 informantes-chave, utilizando como metodologia a amostragem tipo bola de neve. Perguntas préelaboradas foram respondidas pelos agricultores assentados durante o método da turnê guiada. Como resultados, foram identificadas 20 espécies de PANC pertencendo a 12 famílias botânicas, sendo a maioria da família Astereaceae $(38,8 \%)$, localizadas principalmente em pastagens naturais (50\%). As espécies de maior ocorrência nos assentamentos foram a carqueja (Baccharis trimera), a buva (Conyza bonariensis), o picão preto (Bidens pilosa), a beldroega (Portulaca oleracea), as folhas da abóbora moranga (Curcubita maxima) e o caruru (Amaranthus deflexus). Observou-se que o conhecimento dos agricultores acerca das PANC é reduzido e baseado em crenças individuais e valores ancestrais, o que refletiu na ausência do consumo das espécies vegetais. Considera-se necessária a correta identificação botânica das PANC antes da coleta e consumo como alimento, afim de evitar ingerir espécies equivocadas ou tóxicas.

\section{A B S T R A C T}

Unconventional food plants (PANC) refer to all the plants that possess one or more edible parts for humans, being spontaneous or cultivated, native or exotic, which are not included in our daily menu. Family farmers, when they have understanding of the potential of these food plants, are able to diversify their usual food and cultivate them taking advantage of unproductive areas or those of low fertility. The work had as its objective to evaluate the level of knowledge of the farmers resident in rural settlements about the PANC and identify botanically the species present in the locations studied. The research took place between March and June 2019 in three settlements of land reform in Santana do Livramento, RS, with 15 key informants using as methodology sampling of the snowball type. Pre-elaborated questions were answered by the settlement farmers during the guided tour method. As a result, 20 species of PANC were identified botanically belonging to 12 different botanical families, the majority being of the Astereaceae family $(38,8 \%)$, located principally in natural pastures $(50 \%)$. The species of greater occurrence in the settlements researched were gorse (Baccharis trimera), buva (Conyza bonariensis), black prick (Bidens pilosa), purslane (Portulaca oleracea), the leaves of moganga pumpkin (Curcubita maxima) and caruru (Amaranthus deflexus). It was observed that the knowledge of the farmers about the PANC is restricted and based on individual beliefs and ancestral values, which was reflected in the absence of consumption of the vegetable species by those interviewed. It is considered necessary the correct botanical identification of the PANC before collecting and consuming as food, in order to avoid ingesting mistaken or toxic species.
Revista Verde

ISSN 1981-8203

Pombal, Paraíba, Brasil v. 15, n.2, abr.-jun., p.221-228, 2020 doi: $10.18378 /$ rvads.v15i2.7572 


\section{INTRODUÇÃO}

A biodiversidade de espécies vegetais do Brasil corresponde a $20 \%$ do total do planeta, sendo que em sua flora nativa há um total de 46.097 exemplares de espécies, das quais, onde cerca de 4 a 5 mil podem ser consumidas pelos humanos (BURITY et al., 2010; FIORAVANTI, 2016). A riqueza natural da diversidade florística do país ainda é pouco explorada e conhecida para fins alimentícios (KINUPP, 2007), existindo um número reduzido de espécies vegetais que fazem parte da dieta humana.

Esse fator pode estar associado ao aumento da produção agrícola e de monoculturas, onde espécies cultiváveis ganham destaque em produção e pesquisa por apresentarem elevado valor comercial, ao mesmo tempo que espécies endêmicas perdem seu espaço natural e vão sendo negligenciadas na alimentação cotidiana (SILVA et al., 2017).

Há indícios de que no mundo existem cerca de $30 \mathrm{mil}$ espécies de plantas que possuem potencial alimentício, sendo que ao longo da história, 7 mil já foram utilizadas para o consumo humano. Em contrapartida, há uma monotonia em relação à diversidade de alimentos que ingerimos no dia a dia, pois $90 \%$ da alimentação humana provem de apenas 20 espécies de plantas, que em sua maioria, são provenientes de outros países (KINUPP; LORENZZI, 2014).

Nesse contexto, surge o conceito de plantas alimentícias não convencionais (PANC), referindo-se a espécies ou partes de plantas que não são consumidas habitualmente pela população, sendo muitas vezes caracterizadas como ervas daninhas, por crescerem espontaneamente em distintos ambientes (LIBERATO et al., 2019).

Fonseca et al. (2017) afirmam que as PANC possuem uma variabilidade genética que proporciona maior rusticicade, germinando desde hortas domésticas até em campo nativo. Sendo assim, estas espécies não precisam necessariamente ser cultivadas, e sim mantidas e manejadas de acordo com as condições de solo e interesse em sua manutenção e propagação, podendo ser um complemento a alimentação diária da população rural (KELEN, 2015).

Dessa forma, agricultores poderão obter uma renda extra ao incluir as PANC na venda em feiras na cidade, contribuindo com a economia local e a subsistência de comunidades rurais (NESBITT et al., 2010). A soberania alimentar em áreas rurais é fundamental para a permanência dos camponeses neste espaço, pois além de terem o direito de acesso aos alimentos, tem a capacidade de produzi-los, com o controle de sua própria produção, garantindo as suas necessidades nutricionais (STEDILE; CARVALHO, 2011).

A identificação e o consumo das PANC pode ser uma estratégia para manter a diversificação alimentar destas famílias, estimulando a manutenção das florestas nativas e dos campos do Bioma Pampa. De acordo com Santos e Silva (2011), o Bioma Pampa é formado por ecossistemas naturais com alta diversidade e espécies vegetais que podem ser comestíveis. Se realizado de maneira sustentável, o consumo de PANC pode ser considerada como uma forma de utilização com baixo impacto na agricultura, associada à conservação ambiental (KINUPP; BARROS, 2007).
Assim, objetivou-se avaliar o nível de conhecimento dos agricultores moradores em alguns assentamentos de reforma agrária em Santana do Livramento sobre as plantas alimentícias não convencionais.

\section{MATERIAL E MÉTODOS}

A pesquisa foi realizada no período de março a junho de 2019, em assentamentos de reforma agrária localizados na zona rural do município de Santana do Livramento, na região sudoeste do Rio Grande do Sul, na fronteira com o Uruguai (latitude: 30.8897 , longitude: $-55.532330^{\circ} 53^{\prime} 23^{\prime \prime} \mathrm{Sul}, 55^{\circ} 31^{\prime} 56^{\prime \prime}$ Oeste). As comunidades rurais foco de pesquisa foram os assentamentos de reforma agrária denominados de Recanto e Conquista Cerro da Liberdade, situados no Distrito Pampeiro, e Roseli Nunes, situado no Distrito Upamaruti.

Quanto à amostragem dos entrevistados, foi empregada a técnica de rede, conhecida na antropologia como "Network" e nas ciências sociais, como amostragem não probabilística, definida por Patton (1990), Cotton (1996) e Pinheiro (2003) como "Amostragem Bola de Neve" ("snow ball"). A técnica de amostragem tipo bola de neve é uma forma de amostra não probabilística que utiliza um informante-chave para localizar pessoas que tenham o perfil da pesquisa. A partir daí as pessoas indicadas pelo informante-chave, passam a indicar novos contatos dentro do perfil solicitado, e assim sucessivamente, aumentando a rede de informantes do pesquisador, formando uma "bola de neve".

A amostra estudada foi composta por 15 informanteschaves durante as visitas nos assentamentos de reforma agrária situados na zona rural de Santana do Livramento, sendo nove mulheres e seis homens entrevistados.

Para a escolha dos entrevistados, o critério de amostragem foi através da identificação de produtores rurais que produzem hortaliças, tanto para subsistência quanto para comercialização, por se tratar de possíveis conhecedores de PANC. O processo foi se repetindo a partir de novos agricultores incluídos, de forma que as pessoas produtoras de hortaliças e potencialmente conhecedoras de PANC foram validadas pela própria comunidade. Os entrevistados foram comunicados que os dados seriam utilizados apenas para pesquisa científica, sem menção nominal de nenhum dos participantes. Ressalta-se que todos os participantes consentiram com a pesquisa, eram maiores de idade e não tiveram identidades reveladas, obedecendo as exigências do Comitê de Ética da Universidade Estadual do Rio Grande do Sul, de acordo com a resolução $\mathrm{N}^{\circ} 466$, de 12 de dezembro de 2012 do Conselho Nacional de Saúde.

Após estabelecer o contato inicial com os informantechaves, foram realizadas entrevistas semiestruturadas por meio de roteiro com perguntas pré-elaboradas sobre as PANC, onde informações pessoais (idade, gênero, grau de escolaridade, cidade de origem) foram levantadas, além de perguntas relativas ao conhecimento, consumo pela família, formas de utilização, importância na alimentação, se cultiva e comercializa as PANC em feiras locais.

As perguntas pré-elaboradas foram realizadas de forma oral e individualmente a um produtor por domicílio. Concomitante à entrevista, foi utilizado o método da turnê guiada, que consiste 
no acompanhamento junto ao entrevistado pela propriedade rural (MOURA; ANDRADE, 2007), para identificação junto ao mesmo das espécies vegetais de PANC encontradas. Uma vez finalizada a entrevista, pedia-se que o entrevistado indicasse nova pessoa, também conhecedora de PANC e o processo foi se repetindo a partir de novos incluídos. Quando havia tendência à estabilização do número de espécies diferentes de plantas citadas, e o número de espécies não se alterava substancialmente, encerrava-se a pesquisa (MING, 2006).

As espécies foram fotografadas em ambiente natural e identificadas quanto às formas de uso e características botânicas. Após, as mesmas foram listadas pela família, nome científico, nomes populares. As categorias referentes ao ambiente de propagação (em meio à cultura agrícola, horta, fragmento florestal, pasto e pomar), hábito de crescimento (herbáceo, árvore, arbustivo e liana), ciclo de produção (anual e perene) foram determinadas de acordo com Lorenzi (1992). As formas de uso (refogadas em molhos e caldos, in natura, endosperma líquido, polpa, amêndoa, empanada, doces, compotas) foram organizadas com base nas receitas descritas por Kinupp (2007).

Posteriormente, foi realizada a correta identificação das PANC através de pesquisas em bibliografias especializadas, como Kinupp e Lorenzi (2014), Lorenzi e Matos (2008), Lorenzi et al. (2006) e Lorenzi (1992), livros, teses, dissertações e plataformas digitais de artigos científicos, como a Scielo (Scientific Electronic Library Online), Google Acadêmico e portal de periódicos da Capes (Coordenação de Aperfeiçoamento de Pessoal de Nível Superior).

Para a identificação botânica, exemplares de PANC foram coletados durante a pesquisa de campo e posteriormente foram comparados visualmente com as plantas componentes dos herbários didáticos da Universidade Estadual do Rio Grande do Sul (UERGS), unidade em Santana do Livramento, que detém algumas espécies vegetais encontradas no Bioma Pampa.

\section{RESULTADOS E DISCUSSÃO}

Do total da população, $13,3 \%$ não conheciam as PANC, $26,6 \%$ conheciam algumas espécies, mas não tinham conhecimento do seu potencial alimentício, e $60 \%$ conheciam PANC e algumas formas de uso na alimentação. Deve-se ressaltar, que nenhum dos assentados possuíam conhecimento a respeito do termo PANC, havendo a necessidade de perguntar se conheciam alguma planta denominada espontânea/inço/invasora que poderia ser comestível. Esse desconhecimento sobre a identificação e as formas de preparo culinário das plantas alimentícias não convencionais, associado às tendências modernas de homogeneização da alimentação humana, possivelmente tenha refletido na inexistência de utilização de muitas plantas que faziam parte do cotidiano alimentar dos índios, e posteriormente, dos moradores das zonas rurais do Rio Grande do Sul e do Brasil.

Polesi et al., (2017), que realizaram um estudo a respeito da agro biodiversidade e segurança alimentar no Vale do Taquari, RS, através de PANC e frutas nativas, demonstraram que ao questionarem os entrevistados se conheciam o termo PANC, nenhum mostrou ter ciência; no entanto, após explicarem e darem exemplos de algumas espécies, a grande maioria relatou conhecer e já ter consumido PANC.
Os agricultores que possuíam conhecimento empírico acerca das PANC, negligenciavam seu potencial alimentício. Caso semelhante foi encontrado por Lima e Lorenzetti (2016), ao avaliarem o consumo de PANC pela população rural e urbana de Rio Pompa, MG, onde 48,8\% de seus entrevistados conheciam espécies de PANC, mas não tinham o conhecimento que poderiam ser utilizadas como alimento.

Marques (2018), realizou um levantamento etnobotânico da diversidade de PANC no Distrito Federal, e ao analisar o perfil dos entrevistados, observou que $57 \%$ que conheciam espécies de PANC afirmaram ter adquirido este saber através da própria família, mesmo resultado encontrado na presente pesquisa, onde agricultores ressaltaram que o conhecimento a respeito do potencial alimentício das PANC, bem como sua forma de consumo foi herdado de familiares, apesar de não possuírem o habito de consumi-las.

Deve-se ressaltar que os agricultores , ao avistarem algumas espécies vegetais durante a turnê guiada, comentaram sobre seu conhecimento de uso como planta medicinal, em chás, e cataplasmas, ou adicionadas ao chimarrão diário, resultado concordante com o encontrado por Borges e Terra (2019), que ao pesquisarem o conhecimento de agricultores da zona rural de Santana do Livramento, verificaram que as PANC identificadas como medicinais são utilizadas como chás, xaropes, emplastos e para saborizar o chimarrão.

As plantas citadas para fins medicinais foram a carqueja (Baccharis trimera), a tansagem (Plantago major), a erva de bicho (Polygonum acre) e o funcho (Foeniculum vulgare).

A faixa etária dos agricultores variou entre 24 e 78 anos, sendo a maioria (73\%) composta por adultos com idade entre 24 e 59 anos. Este índice revela que a idade dos informantes não influenciou no conhecimento dos mesmos sobre a utilização de PANC, divergindo as conclusões obtidas por Barreira et al. (2015), em estudo realizado sobre o conhecimento e uso de PANC na zona rural de Viçosa, MG, onde os idosos foram os maiores conhecedores do tema.

Todos agricultores realizavam sua atividade profissional principal no meio rural, sendo que $60 \%$ dos informantes eram agricultores (em sua maioria, produtores de soja, milho e frutíferas), $20 \%$ eram pecuaristas de gado de corte, $13,3 \%$ eram pecuaristas de gado de leite e outros $13,3 \%$ constituía-se de uma aposentada e uma dona de casa. Do total, $20 \%$ dos agricultores possuíam uma atividade profissional complementar, sendo um informante comerciante com armazém próprio no assentamento onde residia; uma agricultora que comercializava semanalmente pães e geleias na feira municipal; e uma pecuarista de corte que no período da manhã exercia a função de cozinheira na Escola de Ensino Fundamental Paulo Freire, no assentamento vizinho ao que residia. A relação da atividade profissional que exerciam os agricultores não está interligada ao conhecimento dos mesmo sobre PANC, mas sim o fato de viverem no meio rural e terem acesso a maior diversidade de espécies de plantas no entorno onde vivem.

Para subsistência da família, $80 \%$ dos agricultores relataram que possuíam horta doméstica em sua propriedade, o que contribuía em parte para a complementação da alimentação diária. Os demais dependiam $100 \%$ da compra de alimentação externa para as refeições, já que não cultivavam espécies vegetais 
para a subsistência. Grisa et al. (2010), ressalta a importância da produção para o autoconsumo por agricultores familiares ao possibilitar a autonomia alimentar, caracterizando-se como uma fonte de renda não monetária, pois as famílias acabam economizando recursos na aquisição de alimentos nos mercados, além de servir como uma estratégia de diversificação dos meios de vida ao contribuir com a estabilidade econômica das famílias rurais.

$\mathrm{Na}$ Tabela 1 encontram-se informações sobre as espécies de PANC que os agricultores já possuíam o conhecimento visual (mesmo sem ter o hábito do consumo), além de outras identificadas no local, dados sobre a família botânica, nome popular, nome científico e a forma de consumo.

Tabela 1. Família, nome científico, nome popular, ambiente de propagação, hábito de crescimento, formas de consumo e ciclo de PANC encontradas em assentamentos da zona rural do município de Santana do Livramento, Rio Grande do Sul.

\begin{tabular}{|c|c|c|c|c|c|c|}
\hline Família botânica & Nome científico & Nome Popular & $\begin{array}{l}\text { Ambiente de } \\
\text { Propagação }\end{array}$ & $\begin{array}{c}\text { Hábito de } \\
\text { crescimento }\end{array}$ & $\begin{array}{l}\text { Formas de } \\
\text { consumo }\end{array}$ & Ciclo de vida \\
\hline Amaranthaceae & Amaranthus deflexus. & Caruru & Horta Doméstica & Herbáceo & Refogado & Perene \\
\hline Apiaceae & Foeniculum vulgare & Funcho & Pomar & Herbáceo & In natura & Perene \\
\hline Asteraceae & Hypochearis albiflora & Radite do mato & Pomar & Herbáceo & In natura & Anual \\
\hline Asteraceae & Coniza bonariensis & Buva & Pasto nativo & Herbáceo & Refogado & Anual \\
\hline Asteraceae & Baccharis trimera & Carqueja & Pasto nativo & Herbáceo & In natura & Perene \\
\hline Asteraceae & Galinsoga parviflora & Picão Branco & Horta Doméstica & Herbáceo & Refogado & Anual \\
\hline Asteraceae & Bidens $p$ & Picão Preto & $\begin{array}{c}\text { Fragmento } \\
\text { florestal }\end{array}$ & Herbáceo & Refogado & Anual \\
\hline Cucurbitaceae & Cucurbita aurantia & Folha de abóbora & Horta Doméstica & Herbáceo & Refogado & Anual \\
\hline Musaceae & Musa paradisíaca & $\begin{array}{c}\text { Coração da } \\
\text { bananeira }\end{array}$ & Pomar & Arbóreo & Refogado & Perene \\
\hline Plantaginaceae & Plantago major & Tansagem & Pasto nativo & Herbáceo & Refogado & Anual \\
\hline Polygonaceae & Polygonum acre & Erva de bicho & Pasto nativo & Herbáceo & In natura & Anual \\
\hline Polygonaceae & Rumex robitusifolius & Língua de vaca & Pasto nativo & Herbáceo & In natura & Perene \\
\hline Portulacacea & Portulaca oleracea & Beldroega & Horta Doméstica & Herbáceo & In natura & Anual \\
\hline Verbenaceae & Aloysia gratíssima & Erva santa & Beira de estrada & Herbáceo & In natura & Perene \\
\hline
\end{tabular}

A identificação de espécies da família Asteraceae se destacou durante a pesquisa a campo, onde 38,8\% das PANC identificadas pertenciam a esta família. Esse resultado é influenciado pela caracterização natural da vegetação do Bioma Pampa, com grande ocorrência de espécies dessa família botânica, que é a mais populosa dentre as angiospermas. De acordo com Liesenfeld (2018), a família Asteraceae ocorre predominantemente em regiões tropicais e principalmente em fitofisionomias campestres. No Brasil, é uma das famílias mais diversas, destacando-se principalmente na florística do Bioma Pampa, que no país é restrito ao Rio Grande do Sul. Nos Campos de Areais, uma das fitofisionomias campestres do Bioma Pampa (sudoeste do RS), a Asteraceae é também a família de maior riqueza.

Benke (2016) afirma que, além das gramíneas, vários outros grupos de plantas se destacam pela variedade de espécies campestres, sendo a família das compostas (Asteraceae) a mais diversa representando cerca de 480 espécies nos campos do Rio Grande do Sul.

Quanto ao ambiente de propagação, as PANC foram localizadas em pastagens naturais $(50 \%)$, em pomares $(16,6 \%)$, hortas domésticas $(16,6 \%)$, jardim doméstico $(5,5 \%)$, fragmento florestal $(5,5 \%)$ e em beira de estradas $(5,5 \%)$. Durante a pesquisa, foi possível perceber que no entorno das moradias era constante o uso de roçadas como forma de limpeza das áreas, fator que pode ter influenciado no resultado do ambiente de propagação onde as PANC foram encontradas.

Quanto ao hábito de crescimento, a maioria das PANC encontradas são classificadas como herbáceas (83,3\%), caracterizando-se por possuírem um caule rasteiro, de menor porte, com tecidos pouco lignificados e maleáveis, ricos em água, uma particularidade do Bioma Pampa, onde há predomínio dessas espécies. Os campos do Bioma Pampa são considerados homogêneos quanto à vegetação, compostos por plantas herbáceas em cobertura vegetal contínua e frequentemente permeado por espécies arbustivas (MARQUIORI, 2004).

Em relação as formas de utilização das PANC, o preparo in natura teve destaque $(66,6 \%)$, seguido pela forma refogada $(33,3 \%)$, além de algumas serem utilizadas também de forma medicinal, como mencionado anteriormente.

Durante a pesquisa foram encontradas 20 plantas espontâneas que são consideradas como alimentícias não convencionais, onde elencou-se algumas espécies que merecem destaque através de imagens, em função da ocorrência nos três assentamentos foco do estudo e por terem sido as mais citadas pelos agricultores entrevistados (Figura 1). 
Figura 1. Espécies com maior ocorrência e mais citadas pelos agricultores entrevistados. (A) Carqueja (Baccharis trimera). (B) Buva (Conyza bonariensis). (C) Picão preto (Bidens pilosa). (D) Beldroega (Portulaca oleracea). (E) Folhas de abóbora (Curcubita maxima). (F) Caruru (Amaranthus deflexus).
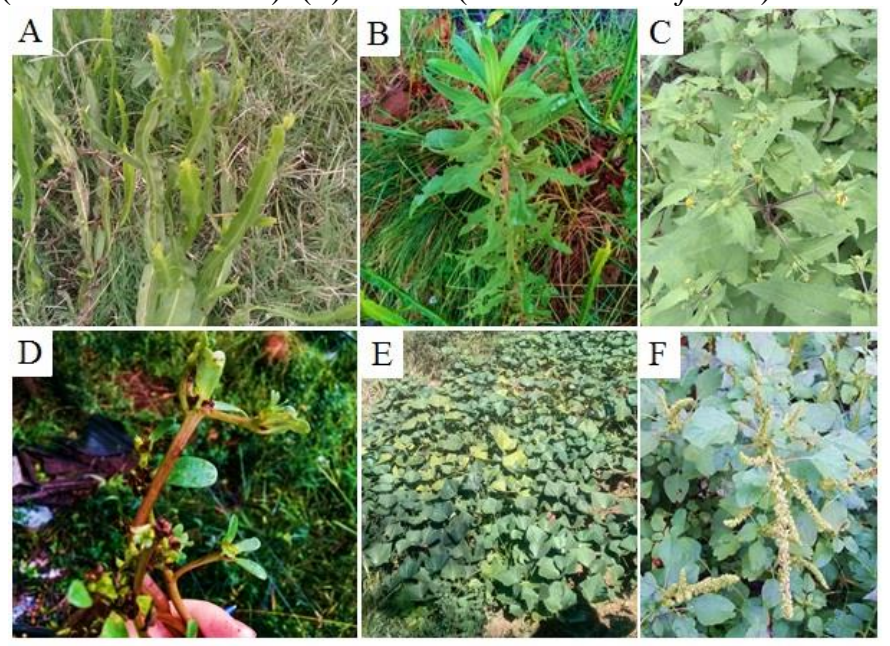

A carqueja (Baccharis trimera), que foi identificada em diversos locais sob pasto nativo durante a pesquisa, é uma espécie nativa da América do Sul, pertencente à família Asteraceae e é também conhecida popularmente como vassoura, cacália-amarga e quina-de-condamine (CORRÊA et al., 1998; BONA et al, 2004).

A carqueja foi encontrada com bastante frequência nos assentamentos foco de estudo, principalmente em campo nativo, além de algumas ocorrências em fragmentos florestais e também à beira de estradas. Esta, foi a PANC mais reconhecida e citada por 73,6\% dos informantes-chave, que ressaltaram utilizá-la apenas para fins medicinais na forma de chá. Uma agricultora entrevistada ressaltou que desde criança toma o chá de carqueja e sempre procura ter a planta em casa, a qual costuma colher pelos campos para posteriormente secar e utilizar quando necessário, junto com outras ervas medicinais.

Kinupp e Lorenzi (2014) cita diversas formas de uso culinário da carqueja, onde a bebida frisante, altamente gaseificada e levemente alcoólica, merece destaque.

Durante a pesquisa, a buva (Conyza bonariensis) foi identificada com grande incidência nos três assentamentos estudados, correspondendo a 26,6\% das citações, sempre ocorrendo em pasto nativo. Porém, os agricultores entrevistados, afirmaram não ter interesse algum em consumir essa espécie, devido a sua grande infestação nos campos de cultivo de soja e milho, que segundo eles, acaba sendo prejudicial à produção comercial.

Pode-se supor que muitas PANC não são consumidas por serem popularmente conhecidas como mato ou inço pelos agricultores, ou por desconhecimento no assunto e também pelo preconceito, como ficou evidenciado no caso da buva durante a pesquisa de campo. Caso semelhante ocorreu com Assis et al., (2016) ao avaliarem os usos e distribuição geográfica das PANC na Bahia, perceberam que a principal limitação para o consumo destas espécies é a falta de conhecimento sobre a utilização culinária e o preconceito por serem reconhecidas como planta invasora.

A buva é considerada uma espécie aromática e picante, que pode ser utilizada de diversas maneiras na alimentação humana, através de suas folhas e ramos foliares novos, podendo ser consumida in natura e também utilizada como condimento de carnes, cozidas e em sopas. A buva ainda possui características medicinais, podendo auxiliar no tratamento contra tosse, hemorroidas e como antiácido (KINUPP, LORENZI, 2014; KELEN et al., 2015).

O picão preto (Bidens pilosa) foi citado por 33,3\% dos agricultores como planta que eles sabiam que poderia ser consumida de forma refogada e como tempero, já que seus antepassados também faziam esse preparo e consumo. As folhas e ramos jovens do picão preto podem ser consumidos in natura ou cozidos, podendo ser acrescentados em saladas, farofas, risotos, entre outras receitas, além de ser uma espécie conhecida pelos seus usos medicinais, pois apresenta funções antioxidantes e altos teores de zinco, cobre e ferro (RANIERI, 2017).

$\mathrm{O}$ picão preto, também conhecido como carrapicho e cuambu, é uma espécie herbácea anual que pertence à família Asteraceae (CORRÊA et al., 1998). Sua propagação ocorre via sementes, sendo facilmente encontrada em pastagens e em calçadas e terrenos baldios de zonas urbanas (GILBERT et al., 2013), sendo que sua ocorrência foi identificada apenas em fragmento florestal durante a pesquisa.

A beldroega (Portulaca oleracea) foi mencionada por $40 \%$ dos agricultores como planta que poderia ser consumida in natura como salada, conhecimento herdado dos avós e pais daqueles que apontaram a espécie vegetal na sua propriedade rural. Todavia, foi comentado que não possuem o hábito de ingeri-la nas refeições, utilizando-a para implementar a alimentação dos suínos. No Brasil, Cândido e Sturza (2016), ao realizarem entrevista sobre a utilização de hortaliças não convencionais com assentados no município de Rondonópolis, MG, verificaram que $33,3 \%$ dos entrevistados relataram utilizar a beldroega como complemento na alimentação de porcos, além de bovinos e equinos.

Para o consumo humano, folhas e talos da beldroega podem ser utilizados em saladas cruas, caldos, sopas, tendo como característica fornecer consistência cremosa aos alimentos (BRASIL, 2010). Nas regiões mediterrâneas, a beldroega é considerada um ingrediente convencional, e em países como os Estados Unidos, China, Holanda e México é consumida em pratos típicos (CORREA, 2017).

A beldroega, também conhecida como salada de negro, brado de porco e onze horas, pertence à família Portulacaceae, sendo uma hortaliça herbácea anual (BOTRAL, et al., 2017). Em Porto Alegre existem agricultores ecológicos que cultivam essa espécie para comercialização em feiras, sendo uma planta de manejo simples, com semeadura realizada diretamente em canteiros definitivos, estando pronta para a colheita em aproximadamente 75 dias após a germinação (KINUPP, 2007; PEDROSA, 2011).

Por apresentar métodos de cultivo e manejo amplamente divulgados na literatura, a beldroega pode ser uma das PANC pioneiras para os agricultores assentados de Santana do Livramento iniciarem uma produção comercial, uma vez que também há relatos de outros agricultores que já produzem e 
comercializam esta espécie, podendo ser um incentivo à implementação do cultivo de PANC no município.

Durante a pesquisa, 33,3\% dos agricultores mencionaram sobre a espécie abóbora moranga (Curcubita maxima), cujas folhas podem ser comestíveis na forma cozida e refogada, informação herdada de seus antepassados. Kinupp e Lorenzi (2014), também mencionam que as flores de várias espécies de abóboras podem ser consumidas, podendo ser preparadas de forma empanada. As gavinhas tenras dos ramos terminais também se consome cozidas, bem como suas sementes, que podem ser torradas para o consumo. Segundo Faber e Cabral (2016), nas sementes de abóbora há uma substancia denominada de cucurbitacina que apresenta ação vermífuga, podendo ser consumida através da fabricação de farinha da própria semente para a elaboração de pães e biscoitos, como por exemplo.

Foi sugerido aos agricultores que já cultivavam abóbora moranga, que poderiam acrescentar as partes alimentícias não convencionais (folhas, flores e gavinhas) no cotidiano da sua alimentação, uma vez que já existe a produção no campo, além do fato de ter sido uma espécie citada pelos próprios agricultores como comestível. Além disso, ao venderam o fruto da abóbora em feiras livres semanais, poderiam comercializar junto as folhas, flores e gavinhas, informando ao consumidor das suas possíveis formas de consumo. As abóboras são consumidas em todo o mundo; porém muitas pessoas desconhecem que a espécie possui partes alimentícias não convencionais, como as flores, gavinhas e folhas.

A espécie vegetal caruru (Amaranthus deflexus) foi uma planta reconhecida por $40 \%$ dos agricultores como PANC, que ressaltaram que o consumo deve ser na forma refogada. Apesar de um agricultor entrevistados ter conhecimento repassado pelos familiares sobre o consumo desta planta, o mesmo não tem o hábito de consumi-la, utilizando somente como fonte de alimento para os suínos que cria em sua propriedade. Quini et al., (2013) afirmam que o caruru é uma planta que pode ser utilizada como forragem animal, onde preferencialmente os talos devem ser utilizados. Na alimentação humana, o caruru é uma planta que se assemelha ao espinafre, podendo ser utilizada para substituir o mesmo, sendo indicado que antes da ingestão seja realizado o branqueamento (KINUPP, LORENZI, 2014).

$\mathrm{O}$ caruru, que pertence à família Amaranthaceae, é uma espécie nativa da América do Sul tropical (BOTREL et al., 2017). No Brasil, o caruru costuma ter maior ocorrência na Região Sul e Sudeste, sendo considera como uma espécie invasora de lavouras anuais (ALMEIDA; SÁ, 2009). Nesta pesquisa, o caruru foi identificado em meio a hortas doméstica e no entorno das moradias dos agricultores, com grande incidência.

De acordo com Almeida e Sá (2009), os grãos do caruru e das demais espécies de Amaranthus ssp. apresentam altos teores de proteínas variando de 12 a 17\%, são também ricos em fibras e possuem baixos níveis de gordura saturada, podendo substituir os grãos de quinoa, cereal muito demandado atualmente pela população vegetariana e vegana, que possuem de 10 a $18 \%$ de proteína em sua composição, além de ambas farinhas não possuírem glúten, fato importante para pessoas que possuem intolerância a essa proteína.

Ao final das entrevistas, percebeu-se que do total das PANC citadas, o caruru e a carqueja foram as espécies vegetais mais conhecidas pelos informantes, mesmo que estes não tenham o hábito de consumi-las. Fonseca et al. (2017), ao realizarem entrevista semelhante com agricultores de municípios da zona sul do Estado do Rio Grande do Sul, citaram mais vezes a fava (Phaseolus lunatus), seguida do caruru.

Ressaltou-se ao público entrevistado sobre a importância da correta identificação botânica das PANC citadas nessa pesquisa, uma vez que identificações errôneas poderiam gerar a ingestão de alguma planta tóxica, fato que causou desconforto entre os agricultores, que preferiram não colhê-las sem a devida orientação técnica.

De maneira geral, foi possível observar que o conhecimento dos agricultores acerca das PANC é reduzido e baseado em crenças individuais e valores ancestrais, o que refletiu na ausência do consumo das espécies vegetais pelos entrevistados. Desta forma, torna-se evidente a necessidade de difundir mais informações relativas às PANC aos agricultores, como a correta identificação botânica, receitas diferentes, formas de utilização e preparo das partes comestíveis, para que possam diversificar e implementar as refeições diárias com novos sabores, agregando nutrientes e evitando gastos desnecessários com a compra frequente de hortaliças e verduras.

Verificou-se que existe uma necessidade de ampliação dos estudos sobre PANC em assentamentos rurais, para que possam ser utilizadas como alimento, propagando sua utilização pelas famílias, favorecendo sua comercialização em feiras, entregas em mercados institucionais e aumento do consumo individual. Há também necessidade de mais pesquisas científicas sobre o valor nutricional, bem como seus efeitos benéficos à saúde humana para tranquilidade do público que pretende fazer uso delas.

\section{CONCLUSÕES}

O nível de conhecimento dos agricultores sobre as plantas alimentícias não convencionais é reduzido e foi herdado dos seus antepassados, porém sendo inexistente o hábito de consumo de PANC nos assentamentos rurais em Santana do Livramento.

\section{REFERÊNCIAS}

ALMEIDA, S. G.; SÁ, W. A. C. Amaranto (Amaranthus ssp) e quinoa (Chenopodium quinoa) alimentos alternativos para doentes celíacos. Ensaios e Ciência, v.13, n.1, p.77-92, 2009.

ASSIS, J. G de A.; GALVÃO, R. F. M.; CASTRO, I. R. de; MELO, J. F. Plantas alimentícias não convencionais na Bahia. Uma rede em consolidação. Agriculturas, v.13, n.2, p.16-20, 2016.

BARREIRA, T. F.; PAULA FILHO, G. X.; RODRIGUES, C. C.; ANDRADE, F. M. C. Diversidade e equitabilidade de Plantas Alimentícias Não Convencionais na zona rural de Viçosa, Minas Gerais, Brasil. Revista Brasileira de Plantas Medicinais, v.17, n.4, 2015. 10.1590/1983-084X/14_100.

BENCKE, G.A. Biodiversidade. In: CHOMENKO, L.; BENCKE, G.A. Nosso Pampa Desconhecido. Porto Alegre: Fundação de Zoobotânica do Rio Grande do Sul, 2016. p. 61-75. 
BONA, C. M. de; BIASI, L. A.; ZANETTE, F.; NAKASHIMA, T. Propagação de três espécies de carqueja com estacas de diferentes tamanhos. Semina: Ciências Agrárias, v.25, n.3, p.179-184, 2004.

BORGES, R.; PEIXOTO, A. L. Conhecimento e uso de plantas em uma comunidade caiçara do litoral sul do Estado do Rio de Janeiro, Brasil. Acta bot. Bras, v.23, n.3, p.769-779, 2009. 10.1590/S0102-33062009000300017.

BOTREL, N.; MADEIRA, N.R.; MELO, R.A.C.; AMARO, G.B. Hortaliças não convencionais/ Hortaliças tradicionais: Beldroega. Brasília, DF: Embrapa Hortaliças, 2017. 3p.

BRASIL. Ministério da Agricultura, Pecuária e Abastecimento. Secretaria de Desenvolvimento Agropecuário e Cooperativismo. Manual de hortaliças não-convencionais. 2010.

BURITY, V.; FRANCHESCHINI, T.; VALENTE, F.; RECINE, E.; LEÃO, M.; CARVALHO, M. de F. Direito Humano a Alimentação Adequada no Contexto da Segurança Alimentar e Nutricional. Brasília: DF. ABRANDH, 2010. 204p.

CÂNDIDO, H. T.; STURZA, J. A. I. Etnoconhecimento e a utilização das hortaliças não convencionais: cenário atual na região de Rondonópolis-MT. Biodiversidade, v.15, n.2, p.191$205,2016$.

COTTON, C. M. Ethnobotany: principles and applications. 1 ed. Chischester: Jonh Wiley e Sons, 1996. 434p.

FABER. J.; CABRAL, D. D. Composição nutricional e análise sensorial de biscoitos elaborados com a farinha da semente de abóbora (Cucurbita maxima). Nutrição Brasil, v.15, n.4. p.210$218,2016$.

FERREIRA KINUPP, V. Plantas alimentícias não convencionais da região metropolitana de Porto Alegre, RS. 2007. 590f. Tese (Doutorado em Fitotecnia) Universidade Federal do Rio Grande do Sul, Porto Alegre. 2007.

FONSECA, C.; LOVATTO, P.; SCHIEDECK, G.; HELLWIG, L.; GUEDES, A. F. A importância das Plantas Alimentícias Não Convencionais (PANCS) para a sustentabilidade dos sistemas de produção de base ecológica. Cadernos de Agroecologia, v.13, n. $1,2017$.

FIORAVANTI, C. A Maior Diversidade de Plantas do Mundo. Pesquisa FAPESP, n.241, p.42-47. 2016.

GILBERT, B.; ALVES, L. F.; FAVORETO, R. Bidens pilosa L. Asteraceae (Compositae; subfamília Heliantheae). Revista Fitos, v.8, n.1, p.51-72, 2013.

GRISA, C.; GAZOLLA, M.; SCHNEIDER, S. A "produção invisível" na agricultura familiar: autoconsumo, segurança alimentar e políticas públicas de desenvolvimento rural. Agroalimentaria, v.16, n.31. p.65-79, 2010.
KELEN, M. E. B. (org.). Plantas Alimentícias não convencionais (PANC): hortaliças espontâneas e nativas. Porto Alegre: Universidade Federal do Rio Grande do Sul, 2015. 45p.

KINUPP, V.F.; LORENZI, H. Plantas Alimentícias Não Convencionais (PANC) no Brasil: guia de identificação, aspectos nutricionais e receitas ilustradas. São Paulo: Instituto Plantarum de Estudos da Flora, 2014. 768 p.

KINUPP, V. F.; BARROS, I. B. I. D. Riqueza de Plantas Alimentícias Não Convencionais na Região Metropolitana de Porto Alegre, Rio Grande do Sul. Revista Brasileira de Biociências, v.5, n.1, p.63-65, 2007.

LIBERATO, P. S.; LIMA, D. V. T.; SILVA, G. M. B. PANC Plantas alimentícias não convencionais e seus benefícios nutricionais. Environmental Smoke, v.2, p.102-111, 2019. 10.32435/envsmoke.201922102-111.

LIMA, P. Z. de; LORENZETTI, E. R. Consumo de plantas alimentícias pela população de Rio Pomba - MG. Cadernos de Agroecologia, v. 11, n. 2, 2016.

LIESENFELD, V. Morfologia e anatomia foliar de Asteraceae do bioma Pampa (Campos de Areais), Rio Grande do Sul, Brasil. 2018.67 f. Dissertação (Mestrado em Conservação e Manejo de Recursos Naturais) Universidade Estadual do Oeste do Paraná, Cascavel, 2018.

LORENZI, H.; MATOS, F. J. de A. Plantas medicinais no Brasil: nativas e exóticas. 2 ed. Nova Odessa: Instituto Plantarum, 2008. $310 \mathrm{p}$.

LORENZI, H.; SARTORI, S.F.; BACHER, L.B.; LACERDA, M.T.C. Frutas Brasileiras e Exóticas e Cultivadas: de consumo in natura. 1 ed. Nova Odessa: Instituto Plantarum, 2006. 650p.

LORENZI, H. Árvores brasileiras: manual de identificação e cultivo de plantas arbóreas nativas do Brasil. 3 ed. Nova Odessa: Instituto Plantarum de Estudos da Flora, 1992. 352p.

MARQUIORI, J. N. C. Fitogeografia do Rio Grande do Sul: Campos Sulinos. Porto Alegre: EST Edições, 2004. 110p.

MING, L. C. Manejo de plantas medicinais na reserva extrativista Chico Mendes - Acre. Revista de Ciências Agroveterinárias, v.5, p.29-43, 2006.

MOURA, C.L.; ANDRADE, L.H.C. Etnobotânica em quintais urbanos nordestinos: um estudo no Bairro da Muribeca, Jaboatão dos Guararapes - PE. Revista Brasileira de Biociências, v.5, p.219-221, 2007.

NESBITT, M.; MCBURNEY, R. P. H.; BROIN, M.; BEENTJE H. J. Linking biodiversity, food and nutrition: The importance of plant identification and nomenclature. Journal of Food Composition and Analysis, v.23, n.6, p.486-498, 2010. 10.1016/j.jfca.2009.03.001. 
OBERDA CARNEIRO MARQUES, L. Levantamento Etnobotânico da Diversidade de Plantas Alimentícias Não Convencionais (PANC) no Distrito Federal. 2018. 41f. Monografia (Graduação em Ciências Biológicas) Universidade Católica de Brasília, Brasília. 2018.

PATTON, M.Q. Qualitative evaluation and research methods. 2 ed. Newbury Park: Sage Publications, 1990. 536 p.

PEDROSA, M.W.; MASCARENHAS, M. H. T.; MAGALHÃES, K. S.; SILVÉRIO, T. T.; SILVA, I. C. S. S.; SEDIYAMA, M. A. N.; FONSECA, M. C. M. F.; SILVEIRA, G. S. R.; OLIVEIRA, F. M.; CARVALHO, E. R. O.; PUIATTI, M.; MADEIRA, N. R.; BORTOLINI, L. O. F. Hortaliças nãoconvencionais. EPAMIG, Belo Horizonte, 2011. 22p.

PINHEIRO, C.U. Técnicas e métodos antropológicos aplicados na Etnobotânica. 1. Ed. Belém: MPEG, 2003. 39 p.

POLESI, R. G.; ROLIM, R.; ZANETTI, C.; SANT'ANNA, V., BIONDO, E. Agrobiodiversidade e segurança alimentar no Vale do Taquari, RS: Plantas alimentícias não convencionais e frutas nativas. Revista Cientifica Rural, v.19, p.118-135, 2017.

QUINI, A. R.; DELAZARI, D. S.; MACHADO, F. M. V. F.; BARBALHO, S. M. Revisão de literatura: Importância nutricional de algumas espécies de Amaranthus sp. Revista Eletrônica de Biologia, v.6, n.1, p.69-81. 2013.

RANIERI, G. R. Guia prático sobre PANC: plantas alimentícias não convencionais. 1 ed. São Paulo: Instituto Kairós, 2017. 44p.

RIBEIRO CORREA, A. Fenologia e produção de mudas de Portulaca oleracea subsp. sativa em clima tropical. 2017. 79f. Dissertação (Mestrado em Agricultura Tropical) Universidade Federal do Mato Grosso, Cuiabá. 2017.

SANTOS, S.; SILVA, L. G. da. Mapeamento por imagens de sensoriamento remoto evidencia o Bioma Pampa brasileiro sob ameaça. Boletim de Geografia, v.29, n.2, p.120-141, 2011. $\underline{10.4025 / \text { bolgeogr.v29i2.12366. }}$.

SILVA, L. F. L.; TECHIO, V. H.; RESENDE, L. V.; BRAZ, G. T.; RESENDE, K. F. M.; SAMARTINI, C. Q. Unconventional vegetables collected in Brazil: chromosome number and description of nuclear DNA contente. Crop Breeding and Applied Biotechnology, v.17, n.4, p.320-326, 2017. $\underline{10.1590 / 1984-70332017 \mathrm{v} 17 \mathrm{n} 4 \mathrm{a} 49}$.

STÉDILE, J. P. e CARVALHO, H. M. Soberania alimentar: uma necessidade dos povos. In: Brasil. Ministério de Desenvolvimento Social e Combate à Fome. Fome Zero: Uma história Brasileira. Brasília, DF: Assessoria Fome Zero, 2010. vol.3, p.144-156.

TERRA, S. B.; VIERA, C. T. R. Plantas Alimentícias Não Convencionais (PANC): levantamento em zonas urbanas de Santana do Livramento, RS. Revista Ambiência Guarapuava

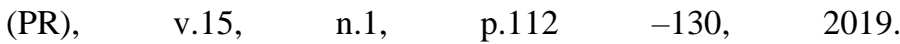
10.5935/ambiencia.2019.01.07. 